\title{
Theoretical and methodological aspects of the competence approach to the evaluation of the organization's personnel
}

\author{
Irina Bagaeva ${ }^{1}$, Oksana Iliashenko ${ }^{1}$ and Alexandra Borremans ${ }^{1}$ \\ ${ }^{1}$ Peter the Great St. Petersburg Polytechnic University, Institute of Industrial Economics, \\ Management and Trade, 195251 St. Petersburg, Russian Federation
}

\begin{abstract}
In the article, from the standpoint of theory and methodology, a competent approach to the evaluation of company personnel is described. The models for assessing the company's personnel from different approaches are presented. The methods used by modern companies for the personnel assessment procedure are highlighted. The meaning of the competence concept and approaches to understanding the essence of the competence concept are given. The concept of competency model is formulated and a variant of this competence model is presented. Deficient moments in the formation of competence models for the evaluation of company personnel were identified.
\end{abstract}

\section{Introduction}

The basis for the survival of any organization, regardless to the form of ownership and scale of production, in the modern world has become personnel with competencies that meet market requirements. Changes in the economy and politics of organizations are quite fast and cardinal. Accordingly, the Russian employee must keep pace with the qualified requirements of the modern market, strive to improve their level of knowledge, skills and habits.

In the face of increasing competition and increasing economic conditions for business development, enterprises are increasingly faced with the need to hire and retain highly qualified personnel. This is especially true for enterprises with a high-tech manufacturing process, which involves the selection of highly qualified specialists. From how correctly the selection process will be built, the economic outcome of the enterprise often depends, as well as the extent to which the enterprise will be successful in a certain segment of the business and attractive as an employer. [1]

Evaluation of employees is one of the most important areas of personnel management, since it is its results that are the basis for making decisions about the promotion, promotion, training, dismissal of employees. The management of companies is interested in evaluating personnel not only as a highly effective specialist, but also as a demonstration of the results of their investments. Therefore, the assessment of the organization's personnel, based on the competence approach, is becoming more and more in demand.

\footnotetext{
*Corresponding author: olgakalinina@,bk.ru
} 
The competence approach provides ample opportunities for describing the professional and personal aspects that are needed to achieve a high level of efficiency of the organization as a whole. There is an opportunity to focus on the key aspects of personal and business qualities that affect the outcome. At the same time, it is still possible to use the concept of competence to describe the knowledge and skills that are expected from employees to effectively fulfill their duties.

Conducting a regular assessment of the development of competencies based on the parameters important for the organization makes it possible to determine the personnel development zones, choose training methods, and also to motivate the development of the necessary organization of competence. A single competence-based database can be used by all personnel management services: for the selection, evaluation, development and remuneration of staff. The competency model is the foundation of the whole personnel management system. It makes it possible to achieve a high level of consistence in the evaluation of candidates - all experts will understand equally what the competence implies. This becomes important today, when there are changes in the functions and practices of working with staff.

The purpose of this article is to consider the theoretical and methodological foundations of the concept, goals and methods of personnel assessment based on the competence approach and consider the concept of a competency model.

\section{Materials and methods}

To build an effective and efficient system of personnel management, it is necessary to take into account a large number of different internal factors characterizing the level of development of management and the degree of competence of members of the organization. Information on such factors is collected, mainly through an analysis of the situation of personnel matters of the organization. A special tool for analysis is staff assessment.

Currently, the literature presents several approaches to the organization's assessment of personnel, combined in different models:

- a procedural (rationalistic) approach. In this approach, the effectiveness of professional activity has the greatest importance. Accordingly, it is primarily focused on improving the efficiency of employees by rationalizing the algorithm of their professional activities. The development of the procedural approach was due to the theoretical provisions of the work of Taylor F., Emerson G., Fayol A., Weber M. Next, it was developed by increasing attention to the assessment of the professional-personal component in the work of specialists. [2] The main motivating force for a specialist should be the effectiveness of his professional activity and the corresponding remuneration, mainly material;

- $\quad$ an organizational (corporate) approach. The organizational approach is primarily focused on evaluating employees as professionals who must identify and link the stability and prospects of their professional future with this organization. Accordingly, the organization provides employees with ample opportunities for self-fulfillment, professional and career growth. And employees, in turn, are focused on increasing the reliability and competitiveness of their organization, seek to comply with internal organizational norms, and in certain situations are ready to set organizational goals above their personalities. A significant contribution to the development of the organizational approach was laid by the works of Shane E., Hofstede G. et al .;

- a humanistic approach. The object of the most careful attention in the humanistic approach to the evaluation of personnel is a person, his job satisfaction and psychological demands. The development of the humanistic approach was initiated by the theoretical provisions of the "school of human relations". A great influence on the development of the humanistic approach was provided by the results of the Hawthorne experiments, during 
which it was proved that the psychological climate in production, the nature of professional relationships among workers, and also the group aspects of activity are in some cases factors that are more important for the performance of workers than the extremely structured organizational environment and competent use of monetary compensation. [3]

In the practice of HR services, there are two additional approaches to the evaluation of the organization's personnel: personal and situational. The personal approach involves evaluating the personality of the employee, his personal and business qualities. The situational approach includes the study of the results of the worker's labor, labor costs, the complexity of labor.

The main thesis of the personal approach (Chenkina B.N., Huchek M.) is that an employee with a complex of professionally significant personal qualities will be effective in his work. The presence of necessary knowledge and skills significantly increases the probability of its success. With a personal approach to assessing employees, management styles are studied, and the psychological qualities of the most successful employees are studied. The main task in drawing up a "psychological portrait" of an employee with the help of psychodiagnostics and expert assessments. Experts argue that judging the abilities, resources and capabilities of the individual only by the results of labor is not only difficult, but impossible. [4]

Supporters of the situational approach (Maslov E.V., Shaunessy D., Shchedrovitsky P.G.) argue that people with different personal characteristics often perform the same type of actions and make the same decisions, demonstrating a similar style of behavior and leadership. People close by personal qualities can make different decisions and behave differently under the same conditions. The basic postulate of this approach is that in the end labor is paid for, and not for quality. Evaluation of personality qualities is always subjective, and the results of labor can be objectively taken into account and measured. Therefore, when evaluating personnel, the principle of modeling various production and management situations is used. The decision on the effectiveness of the activities evaluated is based on the conclusion of experts on the degree of success of the solution of the proposed tasks. The result of labor is expressed not only through the results of the unit's activities (fulfillment of the profit plan, growth of the number of clients, etc.), but also through studying the social and economic working conditions of subordinate personnel. And this is the level of labor remuneration, the degree of labor motivation of staff, the presence of conflicts and the mechanisms used to resolve them, etc. [5]

In practice, a combined approach can be applied with the predominance of one of the vectors (procedural, humanistic, organizational, personal or situational) at different stages of staff assessment.

Within the framework of each of the above approaches, appropriate methods and methodologies for evaluation have been created and are being developed.

Conditionally, all methods of researching an organization can be divided into three main approaches: humanitarian, engineering and empirical. Methods of personnel assessment are the most relevant to the empirical approach, as they are based on the spread of successful industry or functional experience, the use of case-law in decision-making. [6]

Methods of empirical research are divided into quantitative and qualitative.

The most common quantitative method is the questionnaire. One of the types of questionnaires used to assess staff is personal questionnaires:

- multifactorial personality questionnaires (Kettell's questionnaire (16-PF), FPI questionnaire, Leonhard characterological questionnaire);

- questionnaires of motivational characteristics (Rean's questionnaire, pedantry test);

- $\quad$ questionnaires of mental well-being, self-relationship, temperament, values, etc. 
Another important method for assessing staff is the ability tests. They are a specially selected standardized set of tasks that serves to assess a person's potential ability to solve various problems:

- Amthauer's intelligence structure test, Guildford's test, which allows measuring social intelligence, Raven's test provides an opportunity to get an idea of the employee's ability to systematized, planned, methodical intellectual activity.

Qualitative methods of research help to obtain information through depth study of a small amount of material. One of the most frequently used methods is interview.

For the assessment of personnel also use methods that contain signs of both qualitative and quantitative research methods. This is, first of all, business cases. The case formulates the problem that this or that employee of the company should solve.

The KPI (Key Performance Indicator) method. The essence of the management method using KPI is to build a "goal tree". Goals are related to the business objectives of the organization. The method allows you to build an effective system of employee motivation, to find critical points and bottlenecks in the work of units or the organization as a whole in a timely manner.

Nowadays it is important not only to collect several methods together, but to adapt them to the conditions existing in the organization. Here, the professionalism and experience of the specialist guiding the evaluation process has great importance.

Competent approach to the personnel processes of the organization is now the most in demand. Competitiveness of any organization in the modern world depends largely on the competencies of its staff.

The concept of competencies was first outlined by Boyatsis in 1982 in the work "Competent Manager", [7] where competence was defined as the sum of the abilities of a particular person, guiding her behavior to meet the requirements of work and achieve the desired results.

According to other researchers, the term "competence" was put into circulation by V. Makelevil in 1982, when his theoretical study was published. According to his definition: "competence is the range of problems, the scope of activities in which this person has knowledge and experience; set of powers, rights and duties of an official, public organization".

Today two approaches to the "competence" definition were formed in the scientific literature: American and European approach. The American approach defines competence as a description of the employee's behavior: competence is the main characteristic of an employee, who, being able to show correct behavior and, as a consequence, achieve high results in his work. The European approach defines competencies as a description of work tasks or expected results of work: competence is the ability of the employee to act in accordance with the standards accepted in the organization (definition of the minimum requirements that must be achieved by the employee).

\section{Results}

The company needs a certain standard to assess the quality of the employee's work. Such a standard can be a developed competency model. Today, the competence approach extends to all areas of company personnel management and the competency model is the central link of the personnel management system. 


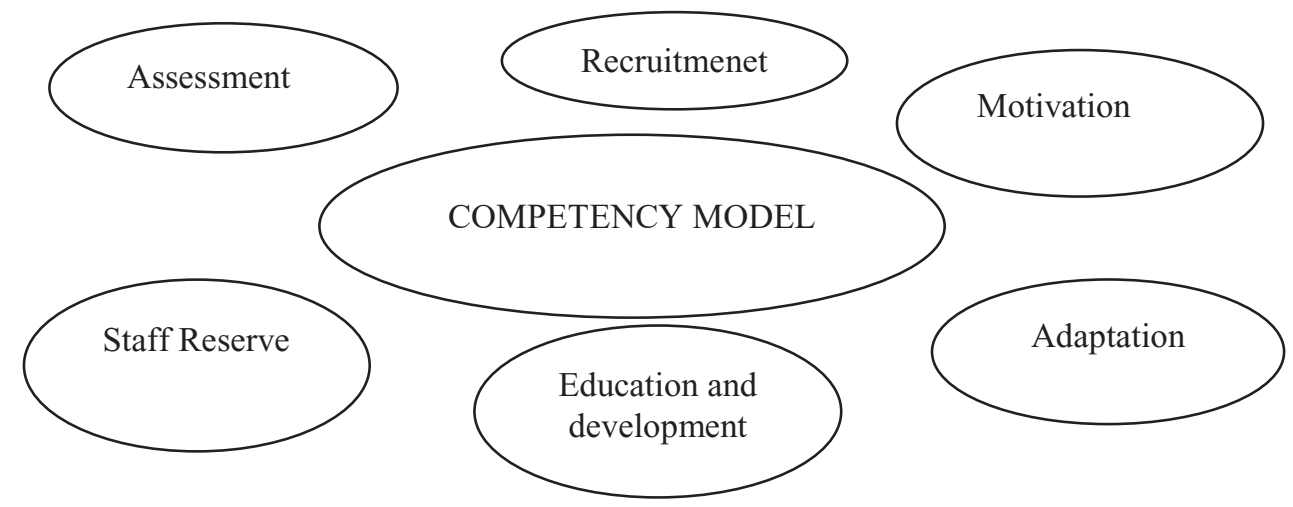

Fig. 1. Scope of the competency management model application in personnel management

Researcher Vetoshkina T. considers the competency model as a full set of competences and behavior indicators that are necessary for the successful performance of the employee's functions, manifested in appropriate situations and time, for a particular organization with its individual goals and corporate culture [8]. Comparison of workers in the set of competencies allows to identify all the gaps in knowledge and skills. The competence approach can be used in the personnel selection, in the formation of the personnel reserve, in carrying out evaluation activities.

Vetoshkina T. distinguishes the following types of competences:

- $\quad$ corporate (or key) competencies support the mission and values proclaimed;

- management competencies applied to all levels of management. Used to assess managers;

- $\quad$ special competencies used for certain groups of positions in different departments.

Personnel Management Specialist I.B. Durakova. singled out the main individual competencies of employees and divided them into four groups: professional, methodical, social, personal [9]:

- professional competencies are the knowledge that the employee has received and can provide to the enterprise;

- methodological competencies are all technologies that promote the use of knowledge gained through professional competence;

- social competencies - all values-necessary, non-work-related expressions of opinions in relation to other workers;

- personal competence (or self-competence) covers such components as selfreflection, self-control, motivation and empathy.

Titova S.V. and L. Yamaliyeva in their research "The Model of Competences of Management Personnel" describes the clusters of the competencies group that L. Spencer adhered to $[9,10]$ :

- $\quad$ achievement and action;

- $\quad$ personal effectiveness;

- $\quad$ cognitive competence;

- $\quad$ creative competence;

- managerial competencies;

- communicative competence.

The framework of this article does not allow us to present the most detailed set of all competency groups offered by researchers of this issue. Generalized standard model includes the following elements [11]: 
- $\quad$ competency clusters - sets of closely related competencies (usually three to five in one set). Each competency cluster has levels - a set of related behavioral indicators;

- competency themselves;

- competencylevels - used most often to create models for specific positions from general models of departments or directorates;

- behavioral indicators are the standards of behavior that are observed in the actions of a person with specific competence.

\section{Discussion}

For successful implementation, the competences model should be clear, understandable and have a simple structure. The more competencies the competency model contains, the more difficult it is to incorporate it into organizational practice. In general, the model can contain from 10 to 12 competencies. When developing a competency model, it is necessary to collect as much information as possible about the employee's work in order to identify those behavior standards that provide the best result. Additional opportunities in the process of collecting and processing information provide appropriate IT solutions that allow tracking and analyzing the employees' work efficiency [12].

Here is an example of the variant of the competences model formation.

- $\quad$ Forming and receiving an order from the top-management of the organization.

At this stage, management of the company discusses resources will be allocated by the organization to support the competences model development: how wide will be the opportunities to work with employees, identifying competencies, whether sufficient information will be provided about the work being carried out and their objectives, and so on.

- $\quad$ Setting the objectives of the competences model development.

At this stage, we formulate the goals. Goals can change when many stakeholders join the development process - they can bring something completely new to the vision and understanding of the project. It is important that all participants in the development project eventually come to a common understanding of the goals.

- $\quad$ Project planning.

At the next stage, we draw up a work plan for the collection, preparation and analysis of the information needed to create the model. Next, we form the work plan for the creation of the model itself, its testing and launch. It is necessary to plan who, when and how will be involved in the course of the project, how will the staff be informed and what will be its content.

- Team selection and selection of analysis techniques.

At this stage, we determine who will collect the necessary information - employees of the company itself, external experts, or both.

- Collect information to identify behavior standards

Sources of such information can be both the employees and managers of the company, and some documents: the company's strategy and business plans, principles and corporate values, documentation related to training of personnel and job descriptions and so on.

- Preparation and analysis of collected information.

Formulation of behavior standards that ensures effective work. Separating them into categories. These categories will be clusters, according to which competences will be distributed.

- Development of a competency model. 
Competencies and clusters are selected by the most appropriate names. Examples of behavior that form the standards are finally divided into competencies and categories, generalized or simplified.

The initial draft of the competency model is obtained. It is necessary to carry out its verification and validation.

- The competency model validation.

The selected competencies are checked. They should reflect the roles, examples and standards existing in the organization.

Validity indicates that employees who have chosen and described competencies do work better than other colleagues. And the staff believes that the proposed competencies are really needed for the successful performance of their work.

After the audit, the competency model is finalized.

- $\quad$ Launching the developed competency model in the company's activities.

\section{Conclusion}

In conclusion, it should be noted that to develop and approve the competency model for the company is only the first step towards its successful use. An important issue in the future work is the issue of informing the company's personnel about the purpose of implementing this model, its significance. Employees of the company should clearly understand how this innovation will affect their work, their further careers, training, the level of compensation and evaluation of the effectiveness of their work. It should also be noted that this should be a regular work to maintain the competency model in an up-to-date and workable state. Another important issue is the need to carry out an economic analysis of projects to improve the company's HR management system [13].

Thus, in a short review, having studied the theory and methodology of the notion of competencies and competence approach, it should be concluded that it is not a tool for assessing staff - it is only an approach.

Before introducing competency models into the practice of the company, it is advisable to answer the following questions:

- how to determine what competencies the staff should have;

- on what scale to assess the competence of staff;

- what is the level of personnel competence suitable for the company;

- what should be taken as a basis for defining competencies.

A standard universal competency model for all companies does not exist. Each company should develop and implement its own individual model.

\section{References}

1. N.E., Clentak, Formation of the personnel department using a team-based approach, Institute of Practical Psychology. National Research University "Higher School of Economics", (2013).

2. O.V., Evtikhov, Modern management approaches in the organization, Actual problems of the humanities and natural sciences, 3, (2011).

3. O.V., Evtikhov, Psychology of personnel management: theory and practice, $(\mathrm{SPb}$, Speech, 2010).

4. O.V., Kiselkina, Construction of a comprehensive system of staff assessment, Institute of Management and Territorial Development, (2014). 
5. L.V., Filippova, Motivation of labor activity of the personnel, Young scientist, 1, 201203.(2013)

6. R., Boyatsis, Competent manager. Model of effective work. (Moscow, GIPPO, 2008).

7. T., Vetoshkina, The role of competence in the management of personnel, Kadrovik. Personnel management, 3, (2010)

8. URL: http://www.k2x2.info/ uchebniki/ upravlenie_personalom/p7.php. (reference date: July 11, 2018)

9. S.V., Titova, L.A. Yamalieva, Model of competences of management personnel, The world of modern science, 1 (16) 3 (2013)

10. L.M. Spencer, S.M. Spencer, Competences at work. Models of maximum efficiency. Moscow: GIPPO, 384p., (2010)

11. N.V., Kalyuzhnaya, Development of the organization's competence model. International scientific journal "Young Scientist", 6, 447-455, (2016)

12. I. Ilin, S. Shirokova, A. Lepekhin, E3S Web of Conferences. 33, 030072017 (2018)

13. A.R., Bril, O.V., Kalinina, I.V., Ilin, Proc. of the 29th Int. Business Information Management Association Conf. - Sustainable Economic Growth, Education Excellence, and Innovation Management through Vision 2020. 2268-2277, (2017). 